\title{
CICLISMO E CICLOTURISMO EM SANTA CATARINA (BRASIL): CARACTERÍSTICAS, MOTIVAÇÕES E INTERESSES
}

\author{
Anderson Sartori \\ Doutor em Turismo e Hotelaria \\ Instituto Federal Catarinense - Campus Sombrio \\ anderprof@hotmail.com
}

Objetivo do estudo: identificar o perfil do ciclista e cicloturista em Santa Catarina, em seus aspectos socioeconômicos, interesses e motivações no ciclismo e usos de aplicativos de monitoramento.

Metodologia/abordagem: quantitativa com enfoque qualitativo, descritiva com levantamento e revisão da bibliografia. Foram utilizados 285 questionários, aplicados virtualmente entre ciclistas e cicloturistas de Santa Catarina, através de amostragem não probabilística intencional e quantificados, por meio de planilhas e gráficos no Excel para análise dos dados através do referencial teórico pesquisado.

Originalidade/relevância: a pesquisa apresenta, de forma inédita, o perfil dos ciclistas e cicloturistas em Santa Catarina, envolvendo dados socioeconômicos, interesses e motivações, usos da tecnologia no acompanhamento e compartilhamento das pedalagens, com aplicativo (Strava), possibilitando novas análises sobre o cicloturismo dentro do turismo.

Principais resultados: as principais motivações para a prática do ciclismo são exercício físico, a realização de novas amizades, conhecer paisagens naturais e patrimônio cultural. O aplicativo é utilizado para automonitoramento de tempo, distância e velocidade durante o percurso e compartilhamento com rede social.

Contribuições teóricas/metodológicas: o planejamento de roteiros de cicloturismo ou o incentivo do uso da bicicleta como atrativo turístico exige atenção às necessidades e expectativas desse público, que se difere do turista usual, requerendo bens e serviços específicos, tanto para si, como para seu equipamento, seja durante os trajetos ou nos momentos de descanso.

Contribuições sociais/para a gestão: as pesquisas dentro dessa temática podem auxiliar no planejamento das políticas públicas de turismo para considerar as expectativas e necessidades dos cicloturistas e ciclistas em geral. Os usos da bicicleta como esporte e/ou lazer ganharam espaço nas últimas décadas, com o compartilhamento das experiências nas redes sociais, com a visibilidade para os destinos e atrativos, que são avaliados pelos praticantes, gerando redes de interesse e mobilização sobre este tema.

Palavras-chave: Turismo. Ciclismo. Cicloturismo. Strava. Santa Catarina.

$\underline{\text { Cite como }}$

American Psychological Association (APA)

Sartori, A. (2021, maio/ago.). Ciclismo e cicloturismo em Santa Catarina (Brasil): características, motivações e interesses. PODIUM Sport, Leisure and Tourism Review, São Paulo, 10(2), 24-53.

https://doi.org/10.5585/podium.v10i2.18084. 


\section{CYCLING AND CYCLING TOURISM IN SANTA CATARINA (BRAZIL): CHARACTERISTICS, MOTIVATIONS AND INTERESTS}

Objective of the study: to identify the profile of cyclists and cyclists in Santa Catarina, in its socioeconomic aspects, interests and motivations in cycling and uses of monitoring applications.

Methodology/approach: quantitative with qualitative focus, descriptive with survey and review of the bibliography. 285 questionnaires were used, applied virtually between cyclists and cyclotourists in Santa Catarina, through intentional non-probabilistic sampling and quantified, using spreadsheets and graphs in Excel for data analysis through the theoretical framework researched.

Originality/relevance: the research presents, in an unprecedented way, the profile of cyclists and cyclists in Santa Catarina, involving socioeconomic data, interests and motivations, uses of technology in the monitoring and sharing of pedaling, with an application (Strava), enabling new analyzes on cycling within tourism.

Main results: the main motivations for cycling are physical exercise, making new friends, discovering natural landscapes and cultural heritage. The application is used for self-monitoring of time, distance and speed during the journey and sharing with social network.

Theoretical/methodological contributions: planning cycling routes or encouraging the use of bicycles as a tourist attraction requires attention to the needs and expectations of this public, which differs from the usual tourist, requiring specific goods and services, both for themselves and for their equipment, either during the journeys or in the moments of rest.

Social contributions/to management: research within this theme can assist in the planning of public tourism policies to consider the expectations and needs of cyclotourists and cyclists in general. The uses of bicycles as sport and / or leisure have gained space in the last decades, with the sharing of experiences on social network, with the visibility of destinations and attractions, which are evaluated by practitioners, generating networks of interest and mobilization on this topic.

Keywords: Tourism. Cycling. Cycling tourism. Strava. Santa Catarina.

\section{CICLISMO Y CICLOTURISMO EN SANTA CATARINA (BRASIL): CARACTERÍSTICAS, MOTIVACIONES E INTERESSES}

Objetivo del estudio: identificar el perfil de ciclistas y ciclistas en Santa Catarina, en sus aspectos socioeconómicos, intereses y motivaciones en el ciclismo y usos de las aplicaciones de monitoreo.

Metodología/enfoque: cuantitativo con enfoque cualitativo, descriptivo con relevamiento y revisión de la bibliografía. Se utilizaron 285 cuestionarios, aplicados virtualmente entre ciclistas y cicloturistas en Santa Catarina, mediante muestreo intencional y no probabilístico cuantificado, utilizando hojas de cálculo y gráficos en Excel para analizar los datos a través del marco teórico investigado.

Originalidad/relevancia: la investigación presenta, de manera inédita, el perfil de ciclistas y ciclistas en Santa Catarina, involucrando datos socioeconómicos, intereses y motivaciones, usos de la tecnología en el seguimiento y puesta en común del pedaleo, con una aplicación (Strava), que permite nuevos análisis sobre la bicicleta dentro del turismo.

Principales resultados: las principales motivaciones para la bicicleta son el ejercicio físico, hacer nuevas amistades, descubrir paisajes naturales y patrimonio cultural. La aplicación se 
utiliza para el autocontrol del tiempo, la distancia y la velocidad durante el viaje y para compartir con la red social.

Aportes teórico/metodológicos: la planificación de rutas ciclistas o el fomento del uso de la bicicleta como atractivo turístico requiere atención a las necesidades y expectativas de este público, que se diferencia del turista habitual, requiriendo bienes y servicios específicos, tanto para ellos mismos como para su equipamiento, ya sea durante los viajes o en los momentos de descanso.

Contribuciones sociales/a la gestión: la investigación dentro de este tema puede ayudar en la planificación de políticas públicas de turismo para considerar las expectativas y necesidades de los cicloturistas y ciclistas en general. Los usos de la bicicleta como deporte y / o ocio han ganado espacio en las últimas décadas, con el intercambio de experiencias en las redes sociales, con la visibilidad de destinos y atractivos, que son evaluados por los practicantes, generando redes de interés y movilización sobre este tema.

Palabras clave: Turismo. Ciclismo. Cicloturismo. Strava. Santa Catarina.

\section{Introdução}

Uma das tendências, nas primeiras décadas do século XXI, é a crescente digitalização e virtualização do mercado, da produção, no comportamento dos sujeitos e das relações sociais. A miniaturização e a ampliação da rede mundial de computadores contribuem para esse desenvolvimento em larga escala de novas formas de comunicação e da compreensão de estar no mundo, com novas racionalidades sendo geradas, transitando entre o real e o virtual. Dispositivos móveis, aplicativos, conectividade, interações e uma gama de bens e serviços tornam-se acessíveis em poucos segundos (Pires, 2017).

Ao mesmo tempo que produz uma visibilidade para o indivíduo dentro de suas redes de contatos e interação, as tecnologias da informação também invisibilizam uma quantidade enorme de dados sobre diferentes aspectos da vida cotidiana, podendo ser utilizados para fins de controle, vigilância ou influenciar comportamentos, conforme argumenta Díaz (2019). Como toda produção tecnológica, ocorrem inclusões e exclusões dentro do sistema econômico que, ao mesmo tempo, buscam popularizar seus bens e serviços para ampliar o consumo e estender o mercado de massas (Hobsbawm, 2003).

A massificação do acesso à tecnologia tem origens com a Revolução Industrial Inglesa (segunda metade do século XVIII), segundo Hobsbawm (2004), e gerou transformações em escala global nos processos de produção, concentração da população em centros urbanos, comercialização e incentivo ao consumo de mercadorias e serviços, principalmente com as 
inovações nos transportes, como a estrada de ferro, motor a combustão, barco a vapor, a rapidez das comunicações postais e todos os processos proporcionados nos séculos seguintes.

A opção pelo automóvel como principal meio de locomoção gerou o crescente congestionamento dos espaços urbanos, uma vez que a oferta de transporte coletivo ocorre, por muitas vezes, de forma precária. A partir desse aspecto, o incentivo a outras formas de deslocamento, como a bicicleta, ficou em segundo plano, embora houvesse mudanças nessa perspectiva, principalmente na Europa. Os espaços públicos do sistema viário necessitam incluir mais atores do que a visão convencional - atualmente focada nos automóveis - com a integração dos sistemas para garantir a mobilidade do morador permanente, bem como do turista, que busca utilizar a bicicleta como meio de deslocamento para fins turísticos, seja em roteiros de curta ou longa distância (Saldanha, Fraga \& Santos, 2020).

Os deslocamentos por lazer foram incentivados, nesse contexto, principalmente a partir de meados do século XIX, através de viagens a vapor regulares e seguras, com capacidade para grande quantidade de pessoas e bagagens, independente do terreno ou das condições aquáticas (Hobsbawm, 2004). O turismo ganhou crescente participação no desenvolvimento econômico dos países, ao longo do século XX e XXI, com as inovações nos transportes (principalmente com os automóveis e o avião, para percursos em longas distâncias), além da oferta de novos produtos e serviços nos destinos turísticos. As tecnologias da informação e comunicação contribuem para o desenvolvimento em larga escala do turismo, na divulgação dos destinos e atrativos turísticos, modificando a relação do consumidor e do marketing, em um processo ativo de avaliação do que é ofertado (Veríssimo e Rodrigues \& Alexandre, 2020).

Para Barbosa, Andrade-Matos e Perinotto (2020), as empresas e os destinos turísticos são impactados pelos conteúdos gerados nas mídias sociais, devido à formação de opinião por parte das pessoas que vivenciaram as experiências turísticas, tanto nos aspectos positivos, como nas dificuldades encontradas. A ampliação dos sites e aplicativos, que agora não somente fazem a divulgação, mas também possibilitam organizar viagens sem a intermediação, é uma das novas ferramentas nesse processo de virtualização da atividade turística, já que a produção de dados pode ser utilizada para ressignificar os destinos e os sujeitos envolvidos diretamente no planejamento e na organização dos atrativos.

O aumento populacional nos centros urbanos é uma tendência ainda maior no século XXI, devido à concentração de bens e serviços nesses territórios, em detrimento ao espaço rural, na maioria dos países, tanto pela concentração industrial, comercial, como pela oferta de bens e serviços. Entre as possibilidades do turismo, a busca por lugares isolados ou mais próximos à 
natureza é recorrente, como alternativa de descanso e lazer frente às conturbações da vida cotidiana das grandes cidades, seja no período de férias, em feriados prolongados ou nos finais de semanas (Silva, 2007). As mudanças nas subjetividades para enfrentamento das pressões crescentes do mercado de trabalho e do cotidiano produzem essa busca por momentos de fuga, influenciados também pelas mídias, pela busca de um corpo saudável, através de exercícios físicos, nos quais a bicicleta é a possibilidade para além dos espaços fechados de academias.

Nesse contexto, o cicloturismo vem ganhando adeptos ao longo das últimas décadas, sendo no Brasil ainda um fenômeno em expansão. Segundo Pedrini (2013), o primeiro circuito de cicloturismo organizado e planejado, intitulado Circuito de Cicloturismo do Vale Europeu, foi implementado em Santa Catarina (em 2006), com trajeto aproximado de $300 \mathrm{~km}$ entre municípios da região, percorrido em vários dias, dependendo das condições físicas do cicloturista.

Na Europa, para efeito de comparação, é estimado que o cicloturismo movimentou cerca de 44 bilhões de euros por ano, com cerca de 2,3 bilhões de viagens de bicicleta que podem ser atribuídos ao valor turístico (Unwto, 2014). O uso da bicicleta no turismo tem potencial econômico e social, contribuindo também para a redução dos impactos ambientais e valorizando os patrimônios naturais e culturais nos destinos, pela ampliação das possibilidades de interação entre cicloturistas e a comunidade local, devido ao tempo de deslocamento com a bicicleta ser menor, em comparação a outros meios de transportes (Resende \& Vieira Filho, 2011). As possibilidades para o turismo com o cicloturismo são viáveis dentro do contexto nacional, especialmente em municípios de pequeno e médio porte, localizados, muitas vezes, em regiões interioranas que contam com a geografia do território como um atributo favorável para o uso da bicicleta, em terrenos pavimentados, ou não.

A aproximação com a natureza, estimulando o exercício físico e a sustentabilidade, motiva os turistas a buscar no cicloturismo uma nova opção de conhecer outros lugares e atrativos. Além disso, a oferta de monitoramento da atividade através de sistemas de posicionamento global (GPS) é crescente com aplicativos para celulares ou dispositivos específicos, que podem ser conectados às redes sociais para compartilhamento (Moreira \& Lovisi, 2017). O deslocamento feito com bicicleta, para viagens curtas ou longas, proporciona uma nova relação com o espaço e tempo, possibilitando uma integração com o meio ambiente e as comunidades locais, como também contribuiu para a divulgação de atrativos e destinos turísticos pelos alcances das redes sociais no compartilhamento de fotos, vídeos e experiências vivenciadas por meio do ciclismo ou cicloturismo. 
Os aparelhos celulares que se transformaram, na última década, em plataformas que possibilitam interações instantâneas através da conectividade com a internet, são uma das ferramentas que contribuem para a visibilidade do ciclismo e cicloturismo, contribuindo para a motivação e o engajamento dos sujeitos dessa prática, principalmente pela influência de amigos e/ou familiares. Fazer parte do grupo, da rede social, torna-se um elemento a mais nesse processo, que agrega a atividade física e a interação no mundo virtual, embora ainda com os desafios e as dificuldades existentes para o desenvolvimento dessa atividade de forma segura, atrativa e planejada com as necessidades e expectativas dos sujeitos.

Dentro desse contexto, além do Circuito de Cicloturismo do Vale Europeu, Santa Catarina ainda possui mais cinco rotas para o cicloturismo organizadas, demonstrando a visibilidade do ciclismo e cicloturismo no estado, além dos trajetos percorridos pelos diferentes grupos, ou de forma individual, que não possuem uma estrutura planejada. O uso de aplicativos e dispositivos eletrônicos, vinculados a redes sociais contribuiu para definição de trajetos e divulgação dos percursos e o contato virtual entre os ciclistas e cicloturistas. A problemática da pesquisa apresentada neste artigo surge da insuficiência de dados e informações sobre quem são os ciclistas e cicloturistas do estado, quais suas motivações e interesses e em que medida utilizam aplicativos de monitoramento e seus impactos nas relações que são estabelecidas.

A pesquisa desenvolvida por Balassiano, Saldanha, DeCastro, Souza, Telles, Garcia e Amaral (2019), sobre o perfil do cicloturista brasileiro, teve cerca de $10 \%$ de respondentes catarinenses, mas os dados são analisados em conjunto com o contexto nacional, não sendo possível identificar nela elementos voltados à realidade estadual. Pelo crescimento das rotas de cicloturismo, bem como das competições que são desenvolvidas ao longo do ano em diferentes regiões do estado, o ciclismo e o cicloturismo vêm ganhando projeção como mais uma possibilidade para o desenvolvimento ou fortalecimento do turismo, com a movimentação de pessoas de forma direta ou indireta pelo uso da bicicleta, seja para competição, ou lazer.

O objetivo geral deste artigo é identificar o perfil do ciclista e cicloturista em Santa Catarina, em seus aspectos socioeconômicos, interesses e motivações no ciclismo e usos de aplicativos de monitoramento. Nesta proposta, não foi abordado o uso da bicicleta como meio de locomoção diário, não sendo discutida diretamente a mobilidade urbana, mas sim os usos do ciclismo no turismo, seja para viagens de longa duração, com pernoite, ou de um dia, no município ou região de moradia do ciclista.

As questões de mobilidade são pertinentes no contexto atual e o uso da bicicleta vem sendo incentivado nacionalmente, embora ainda de forma pontual dentro do contexto das 
grandes cidades e necessitando de estudos mais aprofundados, nas cidades de médio e pequeno porte. O principal meio de transporte individual dos trabalhadores ao longo do século XX foi sendo ressignificado em seus usos, com novos modelos e o incentivo para o esporte, que gerou essa busca pelas viagens com a bicicleta e toda a linha de acessórios de segurança, vestimenta e conectividade, que passaram a atrair a atenção e o interesse de homens e mulheres, de diferentes faixas etárias.

Importante ressaltar que a questão financeira é um limitador para o acesso a bicicletas e aos equipamentos, o que precisa ser levado em consideração no planejamento e na organização do ciclismo e cicloturismo, porque atinge, dependendo do nível, diferentes perfis de interessados. Esse mercado envolve valores elevados, se comparados à compra de bicicletas “comuns" para o dia a dia, restringindo a atratividade, pois gera a necessidade de adequação aos padrões que passam a ser estabelecidos pelos grupos e sujeitos imersos nesse meio, tanto nos aspectos da prática ciclística, como pelo compartilhamento nas redes sociais.

Compreender essas dinâmicas, perfis e formas de interação pode contribuir para novos formatos de rotas e roteiros de cicloturismo, além de proporcionar o incentivo à prática do ciclismo atenta às necessidades e às expectativas de diferentes segmentos socioeconômicos, explorando essas diversidades como um elemento de desenvolvimento sustentável e coerente com as condições dessa multiplicidade de contextos.

\section{Cicloturismo e ciclismo}

As pesquisas sobre cicloturismo e ciclismo têm alcançado expressão nas últimas décadas, com a ampliação e a visibilidade dessas práticas, tanto no aspecto competitivo, como de lazer, com grupos que passam a organizar as atividades ciclísticas, como também a busca por melhorias nas condições de segurança, mobilidade e respeito no trânsito e nas cidades. A produção científica vem acompanhando esse processo, problematizando diferentes aspectos e possibilidades para contribuir com tais discussões, abrangendo diferentes áreas do conhecimento, devido às diferentes demandas encontradas neste campo. Assim, para este artigo, o foco será voltado ao turismo e às contribuições para os objetivos da pesquisa proposta.

Ao realizar a busca pelo conceito de cicloturismo na contemporaneidade, o trabalho de Lamont (2009) tem por objetivo estabelecer parâmetros técnicos para definição, avaliação do tamanho do mercado e analisar os impactos e benefícios do cicloturismo nas comunidades receptoras. Esse autor aponta ser preciso delimitar as atividades que envolvem o cicloturismo, auxiliando os operadores e os responsáveis na gestão de atender às necessidades e expectativas 
dos consumidores dessa atividade. Lamont (2009) propõe a definição de cicloturismo como viagens para regiões diferentes da moradia fixa, com participação ativa ou passiva como motivação principal, inserindo, assim, a participação em competições e as pessoas que viajam para assistir a esses eventos na categoria de cicloturistas. A definição é ampliada com a abrangência da atividade esportiva inserida no cicloturismo, sendo uma perspectiva que difere das abordagens tradicionais sobre a atividade dentro do turismo.

O ciclismo e o turismo, atualmente, segundo Deenihan e Caulfield (2015) não foram objetos de pesquisas com profundidade, sendo os trabalhos existentes voltados à eventos de grande escala, como o Tour de France (competição) e o turismo de aventura em geral. Os autores definem, a partir dos dados coletados em Dublin (Irlanda), que os turistas estão dispostos a ampliar em quase $100 \%$ o tempo de estadia, se tiverem condições para pedalar em espaços com infraestrutura voltada ao ciclismo (ciclovia), sem estar envolvidos diretamente com o tráfego de veículos. Freeman e Thomlinson (2014) também concordam com a escassez das pesquisas, apontando ser preciso constituir estruturas para apoiar estratégias comunitárias de turismo, com o envolvimento do poder público e do setor privado no desenvolvimento de clusters competitivos regionais, com benefícios para os residentes e visitantes.

As pesquisas de Neves e Esperança (2011), Pedrini (2013), Kovačić (2015), Meng e Han (2016), Campos, Santos e Alves (2016), Gonçalves-Junior, Corrêa, Carmo e Arévalo (2016) e Gazzola, Pavione, Grechi e Ossola (2018) convergem ao identificar as relações e experiências culturais estabelecidas entre os cicloturistas e a comunidade local, a interação com a natureza e as possibilidades de desenvolvimento das comunidades receptoras de um turismo sustentável, minimizando os impactos ambientais pelo tipo de atividade realizada. O tempo da viagem é diferente ao estar pedalando, conforme chama atenção Pedrini (2013), gerando proximidade com os aspectos culturais e naturais das comunidades, com significados diferentes daqueles construídos quando se utilizam meios de transporte mais rápidos.

Os trabalhos de Lee, Chen e Huang (2014), Chen e Cheng (2016) e Slavić (2017) analisam as questões logísticas sobre o cicloturismo, como os meios de hospedagem adequados para acomodação do ciclista e seu equipamento, as condições para o deslocamento e a oferta de produtos e serviços adequados ao longo dos trajetos, nos espaços urbanos e, principalmente, nos rurais, que, muitas vezes, se encontram distantes de estabelecimentos para consertos de bicicletas ou venda de produtos alimentícios, por exemplo.

Ainda dentro dessa perspectiva, Lee (2014) explora a perspectiva da demanda tratando de elementos importantes para a satisfação geral na experiência com ciclismo e os principais 
determinantes da frequência do uso da bicicleta a lazer, como recreação e turismo. O autor aponta três atributos identificados na pesquisa para a satisfação do visitante no destino de cicloturismo: sinalização dos trajetos, prestação de serviços de segurança e emergência e qualidade das rotas. A renda mensal é um fator importante para a frequência do turista em rotas de utilização da bicicleta. Desde o passeio de bicicleta, a experiência e frequência do ciclismo de lazer podem ser aumentadas, conforme avalia o autor, modificando as práticas de marketing e de gerenciamento de destino, a partir de ações do poder público e do setor privado que visem à garantia do fornecimento de mantimentos e lojas de conveniência ao longo das ciclovias, desenvolvendo informativos, sistema de sinalização apropriados nas ciclovias e direcionamento de opções de passeios de bicicleta e ciclismo de lazer planejados para turistas de renda média a alta.

Para Saldanha, Fraga e Santos (2015), o planejamento é um requisito importante para o atendimento das especificidades dessa demanda, a fim de proporcionar as condições a experiências memoráveis com a bicicleta em seu uso turístico. Tais fatores, entre outros, podem contribuir com motivações positivas ou negativas para realizar o cicloturismo, conforme identificaram Edra, Costa e Fernandes (2015).

Mrnjavac, Kovacic e Topolšek (2014) discutem a relação das informações com a logística para o turismo com a bicicleta, estudando o caso da Croácia, no que se refere à disponibilidade de dados nos sites de pesquisa. Constatam a diferença das informações nos sites de turismo em geral e nos específicos de ciclismo, que atendem às necessidades de forma adequada. Avaliam como fundamental a aproximação da oferta e da demanda dos destinos turísticos com dados mais completos e detalhados, como infraestrutura e integração com o transporte público, que são considerados elementos importantes para a atração dos turistas que utilizam bicicletas em suas viagens, especialmente as do tipo mountain bike, devido à aproximação com as paisagens e com os elementos da natureza.

As representações sobre o espaço percorrido através do olhar do cicloturista aparecem na discussão realizada por Klos, Miskalo-Cruz e Moraes (2016) que possibilita compreender a percepção sobre o lazer e o espaço turístico no contato entre os sujeitos, seja entre os próprios ciclistas e com a comunidade local. A utilização da bicicleta para o turismo projeta novas possibilidades de produção do imaginário sobre o espaço e as relações estabelecidas, proporcionando aos sujeitos experiências singulares pelo caráter ativo de sua participação ao longo do trajeto ou rota. Trata-se de uma perspectiva que requer planejamento e desenvolvimento de roteiros, que proporcionem essa interação com a paisagem e com os 
aspectos culturais das comunidades, voltando-se à sustentabilidade da atividade em todas suas fases.

Fernández-Latorre (2015) faz a análise entre o capital e o cicloturismo, envolvendo a extensão do território, o interesse cultural, natural e a população local, para o desenvolvimento do turismo, desde que integre os recursos turísticos disponíveis a este capital territorial. A perspectiva do cicloturismo como valorização do território é abordada por Gazzola, Pavione, Grechi e Ossola. (2018), com benefícios às comunidades locais, pelo baixo impacto no consumo de recursos naturais pelos cicloturistas.

Considerando o cicloturismo como prática esportiva dentro da esfera de lazer, do tempo livre ou autorrealização pessoal, para Allué (2019), essas atividades são produtos ou consequência da opção por um estilo da vida que busque romper com as pressões da rotina diária. O cicloturismo se insere como uma prática esportiva, que envolve esporte, lazer e turismo, com crescimento de adeptos e demanda de destinos turísticos adequados às necessidades dos praticantes. Também favorece o contato com a gastronomia e as populações locais, por ser um meio de locomoção de baixa velocidade e que requer mais paradas que outros meios de transporte.

Piket, Eijgelaar e Peeters (2013) definem que os gastos diários de cicloturistas, ao serem comparados com outros turistas, são muito próximos aos do contexto europeu, que pode contribuir de forma significativa para o cicloturismo ser um fator de desenvolvimento das economias rurais que, em muitos casos, não fazem parte dos roteiros do turismo convencional. Na pesquisa realizada pelos autores, sugere-se um potencial econômico direto, de cerca de 7 bilhões de euros, além da menor incidência dos impactos negativos no meio ambiente, do que outras formas de turismo e maior possibilidade de interação com as paisagens e populações locais. Os autores concluem que o cicloturismo é produto turístico que pode ser desenvolvido como uma importante oportunidade de viagem que minimiza os impactos ambientais e prioriza o contato com as áreas rurais, devido ao tempo mais lento de locomoção por parte do cicloturista.

Os processos, conceituados como empoderamento, mobilizados na prática do ciclismo urbano por mulheres foram analisados por Cavalcanti, Santos, Moura e Moura (2019), sob a ótica das tensões e relações de poder vivenciadas pelas ciclistas, no contexto de deficiências dos espaços e políticas públicas para mobilidade por bicicleta nos centros urbanos. Essas problemáticas, de acordo com o estudo, têm impactos concretos nos índices de participação e permanência para as praticantes do ciclismo, aliadas ao medo da violência, que requer, em 
muitos percursos, a participação de ciclistas homens para garantir uma sensação de tranquilidade. O empoderamento feminino, segundo os autores, foi demarcado por vivências de fisicalidade, nas relações de solidariedade e companheirismo experimentadas, tanto na prática esportiva, como de lazer do grupo de ciclismo estudado.

A produção científica sobre o ciclismo e cicloturismo, como chamam atenção Deenihan e Caulfield (2015), Cox (2012) e Lee (2014), embora necessite de aumento de pesquisa sobre o tema, no Brasil, nos últimos anos, se observa o aumento dos estudos nessa área, além do interesse pelo ciclismo como atividade de lazer/recreação e do cicloturismo. As preocupações com a sustentabilidade e mobilidade urbana contribuem para o desenvolvimento de políticas e práticas que incentivam o uso da bicicleta em diferentes momentos.

A implantação de circuitos e rotas para o cicloturismo requer, de acordo com a revisão da literatura apresentada, o conhecimento das demandas e necessidades dos interessados, bem como proporcionar ações nos destinos turísticos para o uso da bicicleta durante a estadia de seus visitantes. O planejamento, conforme apontam Saldanha, Fraga e Santos (2015), é fundamental para atender às especificidades dos ciclistas que usam a bicicleta para o turismo, seja no espaço urbano ou rural, integrando atrativos e as estruturas necessárias ao longo dos percursos.

O cicloturismo apresenta uma série de problemas, tanto para os pesquisadores que o analisam, como para os envolvidos em sua gestão. O cicloturismo e o ciclismo apresentam agendas contrastantes e, muitas vezes, concorrentes, conforme pontua Cox (2012), pelos diferentes usos da bicicleta. A pesquisa do autor conclui que as estratégias para promover o cicloturismo (no caso da Bélgica) também incentivaram o uso da bicicleta como meio de transporte que atende às necessidades sociais de mobilidade e às agendas ambientais. Para o cicloturismo, o mapeamento das rotas, o uso da tecnologia para divulgação e o sistema de posicionamento global (GPS, na sigla em inglês) como guia nos percursos proporcionam consistência e segurança nos destinos para os cicloturistas e ciclistas em geral.

\section{Interfaces da tecnologia no cicloturismo e ciclismo}

Na diversidade de práticas que envolvem o cicloturismo e o ciclismo, a difusão dos aplicativos e dispositivos móveis para localização e monitoramento das atividades em tempo real e seu compartilhamento via internet é uma tendência que vem crescendo a cada ano, com as melhorias técnicas sendo requeridas para atender às novas demandas e expectativas dos praticantes. 
Além do exercício físico e contato com o território e suas populações, o uso da bicicleta impulsiona sites, redes sociais e grupos virtuais de discussão, agregando o valor do compartilhando das experiências, suas motivações, problemas encontrados, facilidades e dificuldades em determinado trajeto ou rota. É um mecanismo, como em outras áreas, de publicidade e influência para os usuários de bicicleta, que necessita de compreensão por parte dos gestores do cicloturismo e do ciclismo, como forma de tornar sua proposta atrativa e ter avaliação positiva pelos usuários, proporcionando fidelidade e atratividade.

Nesse contexto de virtualização do real e suas experiências, Moreira e Lovisi (2017) analisam como as inovações nas tecnologias da informação ganham espaço no uso da bicicleta, com recursos que auxiliam no monitoramento do percurso e desempenho do ciclista, através de dispositivos próprios ou aplicativos para smartphones que utilizam o GPS. Um desses recursos é o aplicativo Strava (compatível com sistemas Android ou $i O S$, em versões pagas ou gratuitas, com restrições nas funcionalidades de análise dos dados), lançado em 2009, que calcula e produz histórico das atividades do usuário (ciclismo, caminhada, corrida, natação, entre outros), reunindo informações sobre o percurso e o esforço físico, caso esteja conectado a dispositivos de desempenho e/ou saúde.

Para o uso no ciclismo, o Strava registra distância percorrida, altitude acumulada, velocidade máxima e média, mapa do trajeto, temperatura, entre outros dados, que podem ser compartilhados nas redes sociais, com a inserção de fotos da atividade. O próprio Strava é projetado como uma rede social, sendo possível seguir amigos, curtir e comentar nas publicações das atividades, além de acompanhar as estatísticas de trajetos de outros ciclistas, com ranking de classificação, ou participar de desafios, como exemplos. É um aplicativo que pode ter finalidade recreativa, além de ser usado para treinamento em competições, por atletas amadores ou profissionais.

Segundo Schwanen (2015), há uma falta de compreensão de inovações e tendências em aplicativos, que reflete não apenas no ritmo rápido de seu desenvolvimento e suas funcionalidades técnicas, mas também em lacunas na conceituação acadêmica da natureza dos aplicativos e seus efeitos dentro das atividades humanas. Os impactos dos aplicativos no incentivo ao ciclismo e ao cicloturismo é um quadro de pesquisa ainda a ser explorado, frente ao discurso da sustentabilidade e mobilidade que ganha espaço no contexto dos problemas ambientais e urbanos, principalmente.

Embora com muitas funcionalidades e opções de recursos, em aplicativos para telefones, como o Strava, ou aparelhos de monitoramento de performance (a exemplo do Garmin), a 
maioria dos ciclistas usa somente os registros de velocidade, tempo e distância, segundo o estudo de Piwek, Joinson e Morvan (2015). Para os autores, o automonitoramento é mais significativo para o ciclismo ocasional ou amador em competições, mas não para os atletas voltados a níveis mais elevados de desempenho.

Para Rivers (2019), plataformas como Strava estão entrincheiradas como campos de prática discursivas em comunidades mundiais, com milhões de usuários registrados, interagindo dentro e fora do ambiente virtual, sendo mediados pelas facilidades da tecnologia. Além do aspecto de monitoramento da atividade e desempenho do ciclista, os recursos do Strava, para muitos usuários, conforme afirma Rivers (2019), têm um grande potencial motivacional por valorizar suas experiências de ciclismo do mundo real, dentro da autonomia individual e representação de pertencimento em uma comunidade com interesses e ideais semelhantes, ou seja, o ciclismo em suas variadas possibilidades.

As transformações tecnológicas no mapeamento em tempo real das atividades físicas, principalmente com o uso de aparelhos celulares, popularizaram e estimularam o desenvolvimento de comunidades para compartilhar suas experiências e dados de desempenho, com o Strava sendo o principal exemplo. A existência de desafios e estatísticas entre os participantes, proporciona a possibilidade de superação de seus próprios limites e dos seguidores, mas, ao mesmo tempo, existe a liberdade de somente compartilhar as pedaladas nas redes sociais, sem a preocupação com os números. A interface entre a atividade física e o mundo virtual estimula o uso do aplicativo e contribui para o turismo, ao disseminar rotas e roteiros a serem visitados dentro dos destinos, utilizando a bicicleta.

O cicloturismo ganha um aliado com o automonitoramento que, junto à sinalização nos trajetos, permite ao interessado percorrer os roteiros podendo acompanhar no seu celular ou ciclocomputador a distância percorrida e demais informações para organizar a intensidade do percurso. A interface entre aplicativos como o Strava e os projetos de cicloturismo necessitam de estudos próprios e aprofundados, para contribuir com o desenvolvimento dessa opção aos turistas, bem como aproximar o destino real do mundo virtual das redes sociais voltadas às atividades físicas.

\section{Metodologia}

A pesquisa tem enfoque quantitativo e qualitativo, sendo descritiva, uma vez que, segundo Gil (2008), tem como principal objetivo a descrição das características de determinada população ou fenômeno, com a utilização de técnicas padronizadas de coleta de dados. Neste 
caso, utilizou-se o questionário, tendo os dados analisados a partir da revisão da literatura sobre o tema. O delineamento da pesquisa é de levantamento, já que, para Marconi e Lakatos (2017), o objetivo é descrever, explorar e explicar um objeto ou fenômeno em estudo, com o questionamento direto às pessoas, para conhecer seu perfil ou comportamento.

Os dados para esta pesquisa foram coletados através da aplicação de questionário, com a utilização da plataforma gratuita "Formulário Google", disponível no aplicativo Google Docs. O link para este questionário, juntamente com as explicações sobre o uso dos dados para fins científicos e autorização para uso das informações, foram enviados para grupos de ciclismo de Santa Catarina e perfil individual de ciclistas, através das redes sociais Instagram e WhatsApp, buscando abranger as diferentes regiões do estado. O público-alvo da pesquisa ficou restrito a respondentes de Santa Catarina, sendo desconsiderados para análise os dados oriundos de outros estados da federação, já que se trata de uma amostragem intencional, conforme Marconi e Lakatos (2017).

O questionário ficou disponível para preenchimento no período de 22 de janeiro a 05 de fevereiro de 2020, sendo composto por 23 questões: seis referentes a dados socioeconômicos e 17 questões sobre a prática do ciclismo e cicloturismo. Para este artigo, foram analisadas cinco questões, sobre dados socioeconômicos (a questão sobre profissão dos sujeitos não foi computada) e nove, sobre a prática do ciclismo, cicloturismo e os aspectos específicos do uso de tecnologias ao pedalar. Os dados coletados são anteriores à oficialização da pandemia do coronavírus, que ocorreu em meados de março de 2020 no Brasil, não sendo, assim, abordados os impactos das restrições de circulação e distanciamento social no tema em análise.

Os dados foram sistematizados para análise em planilhas do Excel, sendo excluídos os questionários com erros de preenchimento, duplicados e que não fossem de residentes de Santa Catarina, totalizando 285 respostas no período em que o questionário ficou disponível, constituindo a amostragem desta pesquisa. O questionário foi organizado com base no trabalho de Balassiano, Saldanha, DeCastro, Souza, Telles, Garcia e Amaral (2019), que apresenta questões estruturadas, levando em consideração os elementos ponderados pelos autores ao elaborarem a pesquisa sobre o perfil do cicloturista brasileiro. $\mathrm{O}$ uso desta referência possibilitou orientar a formulação das questões para a identificação do perfil desse ciclista e do cicloturismo em Santa Catarina, com o uso do referencial bibliográfico como ponto de identificação teórica dos aspectos a serem questionados.

Os dados são apresentados em gráficos e tabelas, com divisão da análise nos aspectos socioeconômicos, para estabelecer o perfil do ciclista e cicloturista, e nos aspectos específicos 
que envolvem o pedalar. Embora a amostragem não possibilite generalizações, apresenta indicativo de tendências dentro da temática do ciclismo e cicloturismo que podem ser aprofundadas por outras pesquisas, ou utilizadas como referência no processo de planejamento e organização de projetos, que envolvem o uso da bicicleta. Na análise dos dados, a organização ocorreu por questão, possibilitando o comparativo dos valores obtidos com pesquisas nacionais e internacionais sobre o tema e que compõem o referencial teórico. Como não foi utilizada uma amostragem probabilística, os dados são tratados de forma descritiva e interpretativa, dentro do objetivo proposto para este artigo.

O turismo é uma construção cultural dentro da história das sociedades, não sendo uma vocação dos destinos, e apresenta diferentes implicações para o turista e as comunidades locais, em uma relação que pode contribuir para a geração de renda, desenvolvimento social, preservação do patrimônio cultural e sustentabilidade, se planejado e executado levando em consideração as potencialidades e fragilidades existentes. A necessidade de construção de base de dados com as informações sobre grupos e interesses com o uso da bicicleta para além dos tempos do trabalho, possibilitará compreender esses fenômenos dentro de séries históricas e suas transformações no espaço e tempo.

Sendo ainda restrita a produção científica sobre o ciclismo e cicloturismo e os usos das tecnologias de monitoramento em tempo real e de desempenho, principalmente no Brasil, as possíveis contribuições teóricas e dos dados coletados para esta pesquisa possibilitarão novas perspectivas de análise e estudos para o planejamento de ações nos destinos turísticos, com fins de desenvolvimento do uso da bicicleta para o turismo e a mobilidade.

\section{Resultados e discussão}

Foram obtidos 285 questionários para esta pesquisa com as respostas (tabela a seguir) concentradas na capital do estado, litoral norte, Vale do Itajaí e Vale do Rio Tijucas (70\% do total). Os municípios dessas regiões possuem grande número de grupos de passeio e/ou competição, além das principais rotas de cicloturismo de Santa Catarina. Os demais respondentes são de várias regiões (listadas após a tabela), compondo uma representatividade que mesmo não absoluta, reflete o quadro contemporâneo dos praticantes do ciclismo e cicloturismo. 
Sartori, A. (2021, maio/ago.). Ciclismo e cicloturismo em Santa Catarina (Brasil): características, motivações e interesses

Tabela 1 - Cidade de origem dos respondentes

\begin{tabular}{l|r|r}
\hline \multicolumn{1}{c|}{ Cidade } & \multicolumn{1}{c}{$\begin{array}{c}\text { Frequência } \\
\text { absoluta }\end{array}$} & $\begin{array}{c}\text { Frequência } \\
\text { relativa (\%) }\end{array}$ \\
\hline Florianópolis & 37 & $13,0 \%$ \\
\hline Itajaí & 29 & $10,1 \%$ \\
\hline São João Batista & 29 & $10,1 \%$ \\
\hline Rio do Sul & 28 & $9,8 \%$ \\
\hline Balneário Camboriú & 18 & $6,3 \%$ \\
\hline Brusque & 18 & $6,3 \%$ \\
\hline Itapema & 16 & $5,6 \%$ \\
\hline Blumenau & 12 & $4,2 \%$ \\
\hline Nova Trento & 12 & $4,2 \%$ \\
\hline Joinville & 11 & $3,8 \%$ \\
\hline Camboriú & 7 & $2,4 \%$ \\
\hline Sombrio & 6 & $2,1 \%$ \\
\hline Taió & 6 & $2,1 \%$ \\
\hline Lontras & 5 & $1,7 \%$ \\
\hline Outras & 42 & $14,7 \%$ \\
\hline Não responderam & 9 & $3,1 \%$ \\
\hline
\end{tabular}

Fonte: O autor, 2020.

No caso dos demais municípios de origem dos respondentes, que correspondem a 14,7\% do total (conforme a tabela 1), temos, com três ou menos respostas: Antônio Carlos, Araranguá, Canelinha, Canoinhas, Curitibanos, Ituporanga, Jaraguá do Sul, Navegantes, Porto Belo, Rio do Oeste, Rio dos Cedros, Rio Rufino, Rodeio, Santa Cecília, Santa Rosa do Sul, São Bento do Sul, São Joaquim, São José, São Miguel do Oeste, Tijucas e Trombudo Central. Embora com poucas respostas, o questionário atingiu as diferentes regiões de Santa Catarina, possibilitando gerar evidências e possíveis interpretações sobre o ciclismo e cicloturismo no estado.

Do total de respondentes, $53 \%$ são do sexo masculino e $47 \%$ do sexo feminino, demarcando, no contexto da pesquisa, uma proximidade significativa entre os dois grupos, com a crescente participação das mulheres no ambiente do ciclismo. Para fins de comparação dos dados, o relatório geral sobre o perfil do cicloturista brasileiro aponta que $25,5 \%$ dos respondentes se declararam como mulheres e quase $74 \%$ como homens (Balassiano, Saldanha, DeCastro, Souza, Telles, Garcia \& Amaral 2019).

Tomando como exemplo a abordagem do conceito de empoderamento, realizada por Cavalcanti, Santos, Moura e Moura (2019), a temática de gênero no ciclismo e cicloturismo é uma dimensão que necessita de uma discussão mais ampla. Uma série de fatores mobilizam o interesse das mulheres em pedalar, ao mesmo tempo que outros elementos são negativos, como as questões de segurança e machismo. A criação de grupos de ciclismo é um fator que ganha força e a presença das mulheres tem ganhado espaço, em grupos mistos, ou somente femininos. 
Santa Catarina apresenta alguns exemplos, que participaram desta pesquisa, como: Pedal Feminino Batistense (São João Batista), Bruxas da Bike (Florianópolis), Cabelos ao Vento (Rio do Sul), Elas e as Magrelas (Brusque) e Elas Pedalam Team (Florianópolis).

A faixa etária predominante vai dos 21 aos 40 anos (55\% do total), mas com significativa presença de respondentes com mais de 41 anos, com $41 \%$, conforme figura a seguir. Os extremos das faixas etárias, abaixo dos 20 anos e acima dos 61, possuem menor número de praticantes. São faixas etárias distintas nos aspectos de capacidade física, mas que podem ser mobilizadas para a prática do cicloturismo, com as devidas adequações.

Figura 1 - Faixa etária

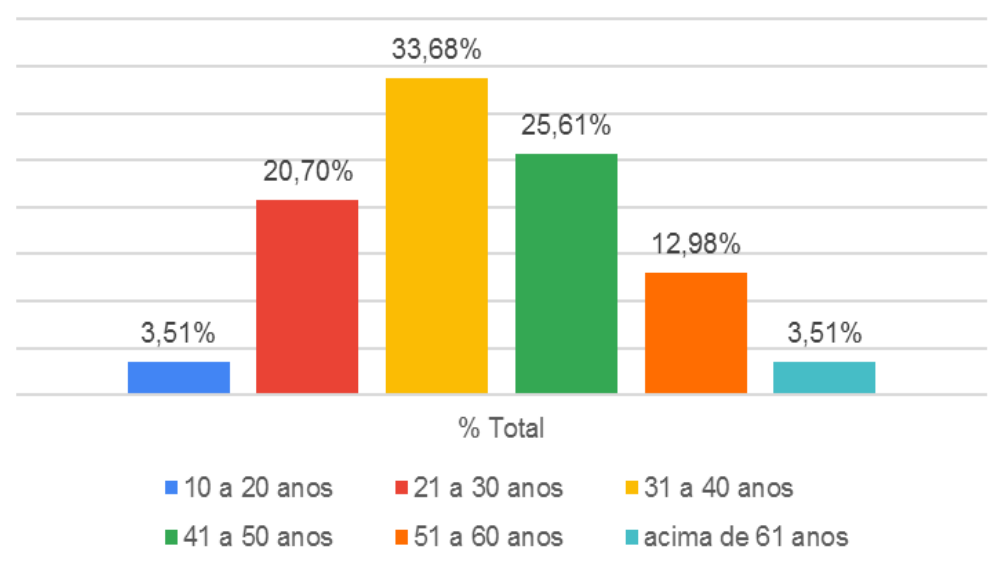

Fonte: O autor, 2020.

O fator renda é importante na discussão que envolve o uso da bicicleta, por ser um mercado em expansão, com uma ampla gama de produtos e serviços, com equipamentos e componentes de valores nem sempre acessíveis. Adquirir a bicicleta e os equipamentos básicos de proteção e manutenção requerem um custo maior ou menor, dependendo da qualidade ou objetivos do pedalar. 
Figura 2 - Renda mensal

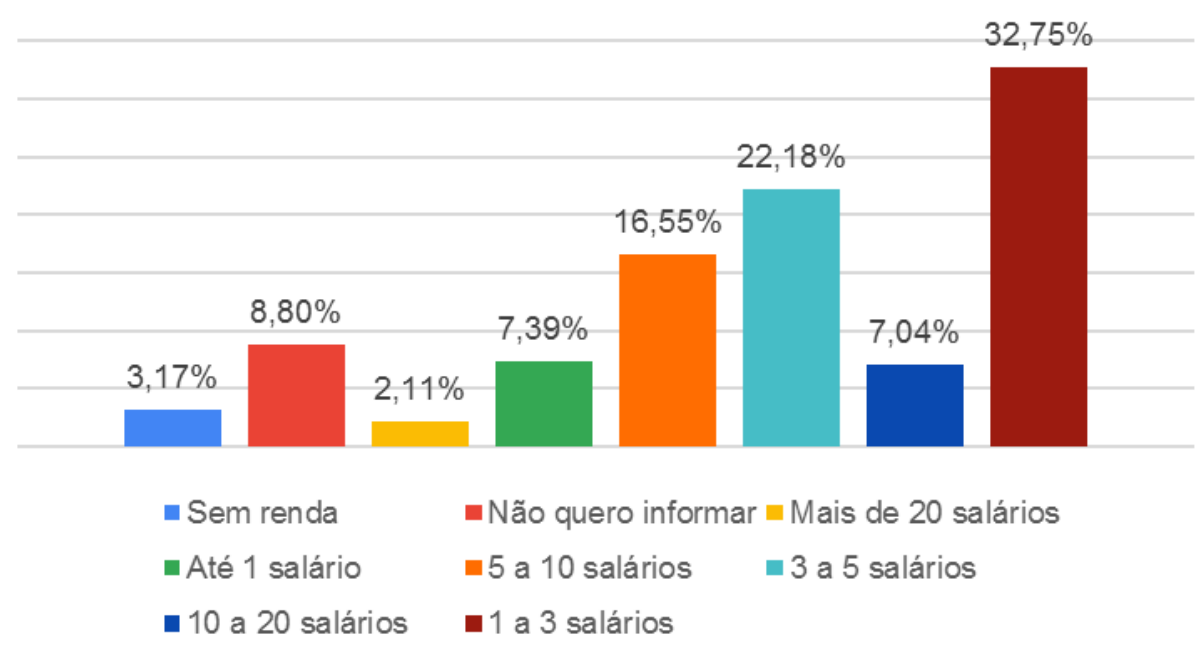

Fonte: O autor, 2020.

De acordo com as respostas obtidas com a presente pesquisa, observou-se o predomínio de respondentes que integram a faixa de um a três salários como renda principal, em seguida, três a cinco salários mínimos, que se aproxima dos dados de escolaridade, sendo a maioria dos respondentes com ensino médio (25\%) e ensino superior (60\%), demarcando uma posição no mercado de trabalho com salários acima do mínimo. A relação idade, renda mensal e escolaridade precisa ter seus fatores analisados em conjunto, para adequar a infraestrutura dos praticantes do ciclismo às suas necessidades e expectativas, conforme abordam Piket, Eijgelaar e Peeters (2013), sendo os gastos diários desse público no destino próximos aos dos demais turistas.

A maioria dos respondentes participa de algum grupo organizado ou equipe esportiva de ciclismo, representando $71 \%$ do total, que pode ser considerado um incentivo para pedalar, seja pela motivação ou sensação de segurança ao realizar um trajeto. A importância do planejamento, como chamam atenção Saldanha, Fraga e Santos (2015), é significativa para atender às necessidades e experiências desses grupos, que utilizam mais serviços que o atendimento ao sujeito que utiliza a bicicleta de forma individual. A fidelização desses grupos e/ou equipes é um atributo a ser levado em consideração nos projetos de ciclismo e cicloturismo, seja na prática do pedalar, como na divulgação por meio das redes sociais, sobre a avaliação da experiência proporcionada, que pode gerar o interesse de outros grupos. A coletividade ganha força na formação desses grupos, com laços de solidariedade que são partilhados e possibilitam também a mobilização por melhorias, seja na sinalização ou segurança nos trajetos, além de incentivar outros sujeitos a buscarem a bicicleta como opção de esporte, lazer ou competição. 
Interessante observar que grande parte, conforme figura a seguir, pedala há menos de três anos, enquanto somente $15 \%$ tem mais de dez anos de pedaladas. Esses dados demonstram como o ciclismo e o cicloturismo são emergentes, se aproximando do contexto histórico da criação do primeiro roteiro de cicloturismo no Brasil (Pedrini, 2013).

Figura 3 - Tempo que pedala

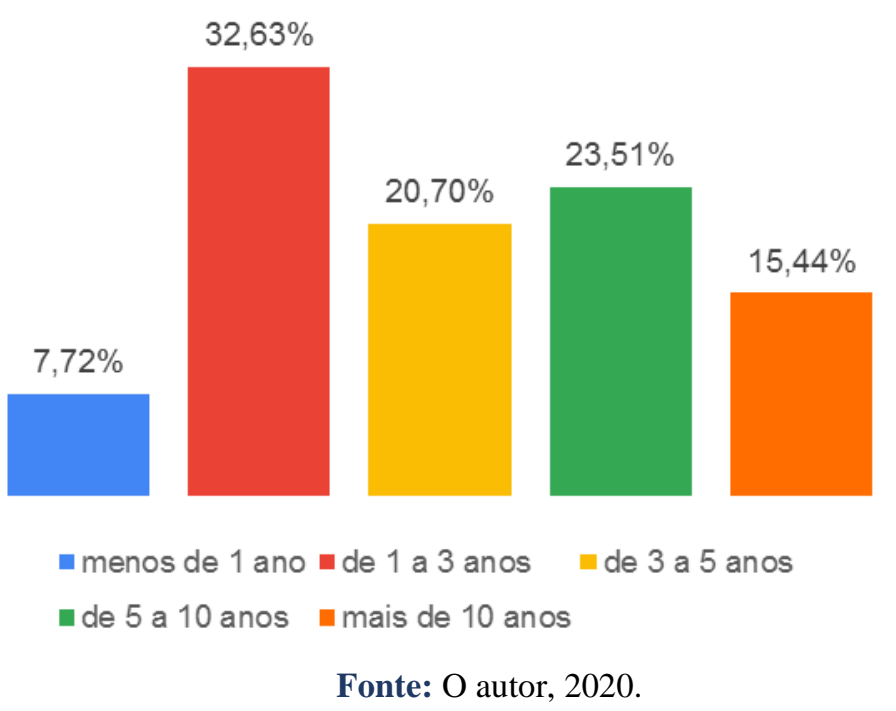

A relação direta entre o desenvolvimento dos roteiros de cicloturismo e a difusão do uso da bicicleta para além de deslocamentos cotidianos é um tema a ser pesquisado no contexto catarinense, para identificar as motivações que incentivam os sujeitos a buscarem a bicicleta frente a outras possibilidades de atividade física e lazer, o que equivale aos 32,63\%, por exemplo, que estão de um a três anos pedalando. Como as políticas públicas são incipientes na mobilidade ciclística, outros fatores são responsáveis por este interesse.

Pedalar é uma atividade realizada com amigos, remetendo à questão sobre a participação em grupo ou equipe esportiva, com $62 \%$ dos respondentes realizando tal prática com amigos, seguidos por $26 \%$, que preferem estar sozinhos. Embora Santa Catarina possua inúmeras equipes de ciclismo e competições ao longo do ano, um pequeno percentual dos participantes realiza treinos com a equipe. Diferentemente do contexto europeu Deenihan e Caulfield (2015), as competições de alto nível, no Brasil, por exemplo, atraem poucos atletas não profissionais, devido aos custos elevados e à escassez de patrocínio, sendo predominante o amadorismo no que se refere ao esporte com bicicleta. 
Figura 4 - Com quem pedala?

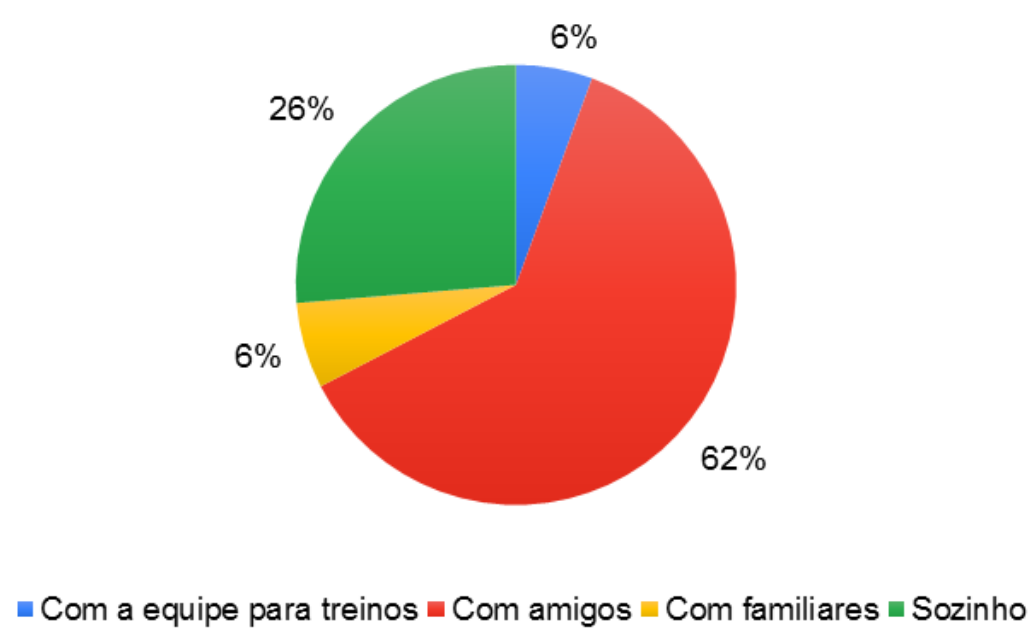

Fonte: O autor, 2020.

A frequência do uso da bicicleta ocorre de uma a três vezes na semana para a maioria (58\%), com somente $3 \%$ do total de respondentes pedalando todos dos dias da semana. No geral, os dados apresentam um uso significativo durante a semana e não somente em feriados ou finais de semana, o que sugere o uso da bicicleta no período noturno, devido ao horário comercial de trabalho, que acaba limitando os horários disponíveis para a prática do ciclismo ou cicloturismo durante a semana.

Figura 5 - Pedais na semana

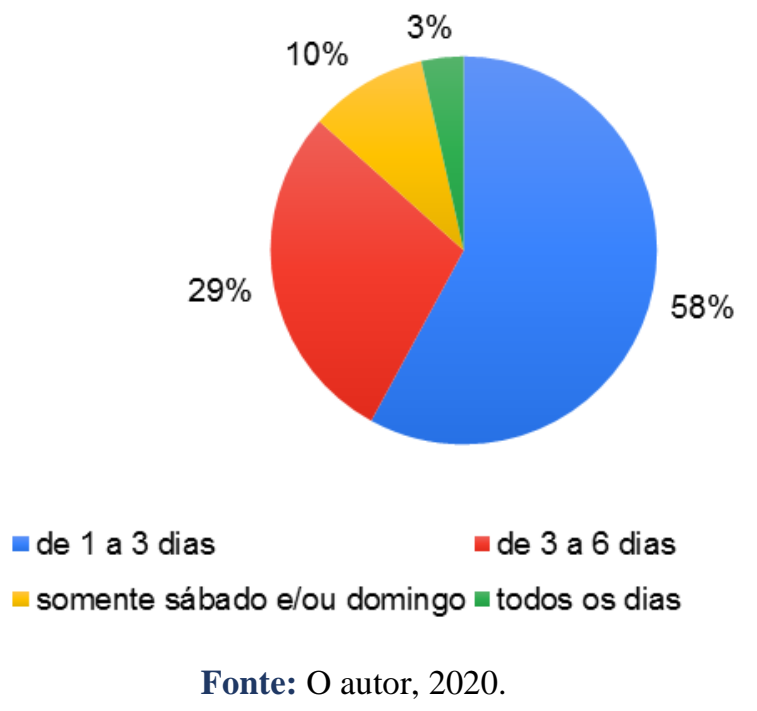

Importante observar esta questão para não atrelar somente o uso da bicicleta no período diurno, uma concepção que pode predominar por envolver atividade ao ar livre. O planejamento 
de atrativos para o cicloturismo deve também levar em conta a possibilidade do turista poder usufruir de estruturas para realizar o trajeto à noite, principalmente no verão e pelas altas temperaturas que inviabilizam a atividade, por questões de desgaste físico. O uso de GPS durante o trajeto, seja em aplicativo ou ciclocomputador, é outro fator que contribui para o autoguiamento noturno, quando o turista ou cicloturista estiver em terrenos que desconhece, por exemplo.

As motivações que prevalecem na escolha pela prática do ciclismo são o exercício físico (29\%) e conhecer paisagens naturais (24\%), sendo que nesta questão havia a possibilidade de assinalar mais de um item. O interesse em conhecer o patrimônio, tanto natural, como cultural, se somados, equivalem a $35 \%$ do total, demonstrando a potencialidade de roteiros de cicloturismo que possam proporcionar essa condição.

Tabela 2 - Principal(is) motivação(ões) para praticar o ciclismo

\begin{tabular}{l|r|r}
\hline \multicolumn{1}{c|}{ Alternativas } & Frequência absoluta & Frequência relativa \\
\hline Exercício físico & 258 & $29,22 \%$ \\
\hline Conhecer paisagens naturais & 208 & $23,56 \%$ \\
\hline Conhecer patrimônio histórico-natural & 101 & $11,44 \%$ \\
\hline Interação com moradores dos locais visitados & 54 & $6,12 \%$ \\
\hline Realizar novas amizades & 147 & $16,65 \%$ \\
\hline Trajetos sem muitas dificuldades técnicas/físicas & 44 & $4,98 \%$ \\
\hline Competir com outros ciclistas & 71 & $8,04 \%$ \\
\hline
\end{tabular}

Fonte: O autor, 2020.

Os dados ainda apontam que realizar novas amizades (16,6\%) é um fator relevante, já que envolve as relações interpessoais estabelecidas ao longo dos trajetos, sendo um componente diferente ao ser comparado com outros tipos de turismo, pelo interesse em comum pelo pedalar e a possibilidade de manutenção de vínculos e viagens com esse mesmo objetivo. A relação dos grupos de ciclismo reforça esses laços de identidade e pertencimento, motivando a realização de novos desafios fora de sua região de origem, bem como reforça Rivers (2019): esses laços são fortalecimentos na comunidade virtual ao publicar suas atividades no Strava e/ou compartilhando em outras redes sociais com o mapa do trajeto ou fotos durante o percurso.

Chama atenção a baixa frequência no interesse pela interação com moradores locais, muitas vezes, ocasionado pela ausência de serviços estruturados nos trajetos, dificultando o contato com as comunidades locais. Os trabalhos de Lee, Chen e Huang (2014), Chen e Cheng (2016) e Slavić (2017) abordam a importância das questões logísticas e de infraestrutura apropriada para o cicloturismo, para a satisfação da demanda, bem como a receptividade e hospitalidade adequadas por parte das comunidades receptoras. 
Sartori, A. (2021, maio/ago.). Ciclismo e cicloturismo em Santa Catarina (Brasil): características, motivações e interesses

Reportando a realidade catarinense, onde predominam municípios de médio e pequeno porte, a elaboração e divulgação de rotas para o cicloturismo necessita do envolvimento para o planejamento de diferentes segmentos sociais e políticos, não somente municipais, mas também regionais, devido às distâncias a serem percorridas, como é o caso do Circuito do Vale Europeu (cerca de $300 \mathrm{~km}$ ). Outro ponto importante é a certificação da realização desses trajetos, conforme o caso de estudo de Pedrini (2013) demonstra: a necessidade de percorrer todo o roteiro para, ao final, receber a comprovação da realização. No contexto dos dias necessários, como no caso do Vale Europeu - cinco dias, seguindo o proposto pela organização -, torna-se inviável sua realização em períodos fora das férias. A possibilidade de percorrer trajetos menores em roteiros de cicloturismo, em diferentes dias, e não em sequência, é uma alternativa a ser explorada, a partir do que os dados apontam sobre o tempo disponibilizado para pedalar, de acordo com os participantes desta pesquisa.

O aplicativo Strava é utilizado por $87 \%$ dos respondentes, o que possibilita, além do acompanhamento da atividade em tempo real, a interação na própria interface do aplicativo através do celular ou com a publicação em redes sociais. Os 13\% restantes dos envolvidos nesta pesquisa não utilizam o referido aplicativo. O quadro a seguir, referente ao uso do aplicativo Strava, aproxima seus números das conclusões da pesquisa de Piwek, Joinson e Morvan (2015).

Quadro 2 - O Strava, caso utilize, é uma forma

\begin{tabular}{|l|c|}
\hline \multicolumn{1}{|c|}{ Alternativas } & Percentual \\
\hline De monitorar e acompanhar o seu desempenho nos percursos & $29 \%$ \\
\hline De definir os percursos e a localização durante o trajeto & $20 \%$ \\
\hline De acompanhar e interagir com os resultados dos treinos de amigos & $16 \%$ \\
\hline De compartilhar suas atividades nas redes sociais & $15 \%$ \\
\hline De planejar e acompanhar o seu desempenho para competições & $9 \%$ \\
\hline De competir para superar os resultados dos outros ciclistas nos segmentos & $6 \%$ \\
\hline Não responderam & $5 \%$ \\
\hline
\end{tabular}

Fonte: O autor, 2020.

Como era uma questão aberta, com a possibilidade de assinalar mais de uma opção, a pesquisa obteve 220 respondentes, representando mais de $75 \%$ do total, bem próximos aos $80 \%$ identificados no trabalho de Piwek, Joinson e Morvan (2015), com itens muito semelhantes, que envolveram monitoramento e acompanhamento do desempenho, representados por distância, tempo e velocidade. 
Sartori, A. (2021, maio/ago.). Ciclismo e cicloturismo em Santa Catarina (Brasil): características, motivações e interesses

A socialização das atividades de forma virtual também tem uma grande atratividade no uso do Strava, com 31\% de interessados nesta possibilidade, ao se somar os itens interação com o resultado dos treinos de amigos e compartilhamentos em redes sociais. O elemento competitivo não apresenta uma motivação para o uso do aplicativo, embora 43 respondentes (15\% do total) indiquem realizar tal uso.

Predomina ainda o lado recreativo e de lazer, no que se refere ao ciclismo e ao uso para compartilhamento da experiência no contexto desta amostra. A interface entre o aplicativo e as redes sociais é um fator de impacto na decisão dos sujeitos que acompanham sua atividade e socializam essas informações. Os caminhos percorridos, velocidades, tempo, a bicicleta utilizada e o tipo de terreno do trajeto são algumas das informações que geram possibilidades de análises para definições de estratégias para o cicloturismo, por exemplo, como vem sendo proposto no espaço urbano para as questões que envolvem a mobilidade.

A escolha dos trajetos também é definida com base em indicações de outros ciclistas e uso de aplicativos, como Whatsapp e Strava, conforme o Quadro 3.

Quadro 3 - Para escolher os trajetos, busca informações

\begin{tabular}{|l|c|}
\hline \multicolumn{1}{|c|}{ Alternativas } & Percentual \\
\hline Indicações de outros ciclistas & $31 \%$ \\
\hline Nos grupos de Whatsapp & $22 \%$ \\
\hline Em publicações no Strava & $18 \%$ \\
\hline Somente realizo percursos que conheço & $8 \%$ \\
\hline Em publicações no Facebook & $6 \%$ \\
\hline Em publicações no Instagram & $6 \%$ \\
\hline Em sites especializados & $4 \%$ \\
\hline Reportagens ou programas televisivos & $3 \%$ \\
\hline Em compartilhamentos no Wikiloc & $2 \%$ \\
\hline
\end{tabular}

Fonte: O autor, 2020.

As interações nos aplicativos geram esse canal de discussão e motivação para organização de pedais em grupos ou a definição de novos trajetos a serem explorados. Analisando os dados, sites especializados, redes sociais e outros meios de informação ainda não alcançaram a preferência dos ciclistas, na busca de opções para pedalar, assim como os roteiros de cicloturismo que ainda carecem de uma divulgação mais ampla para ter maior visibilidade fora da região que estão localizados. 
Sartori, A. (2021, maio/ago.). Ciclismo e cicloturismo em Santa Catarina (Brasil): características, motivações e interesses

No contexto que aborda que as tecnologias da informação ganham mais espaço, é importante a compreensão dos impactos desse fenômeno nas atividades físicas e, principalmente, nas formas de fazer turismo que envolvem diretamente a utilização do corpo, como no turismo de aventura e suas múltiplas práticas. O uso da bicicleta com fins turísticos é uma tendência que ganha adeptos e movimenta a economia local de diferentes formas, com os aplicativos e redes sociais sendo influenciadores desse processo.

O cicloturismo, em contraponto à proposta de conceituação de Lamont (2009), pode ser definido como viagens a regiões próximas ou diferentes da moradia fixa do sujeito, guiadas ou não, individualmente ou em grupos, com a participação ativa e as experiências culturais e ambientais ao longo da rota ou percurso escolhido. Não restringir o conceito sobre viagens distantes da moradia a mais de um dia é importante, pois muitos ciclistas utilizam a própria bicicleta para chegar até o destino, em viagens de ida e volta no mesmo dia, não necessitando do deslocamento com veículos em parte do trajeto. A motivação do cicloturista é o principal atributo a ser considerado na sua relação com o turismo e a oferta de bens e serviços, em suas mais diversas singularidades.

As competições esportivas, embora movimentem o turismo do local em que acontecem, possuem motivações e objetivos ao longo do trajeto que envolvem desempenho, tempo e distância que precisam ser superados. Allué (2019) define as atividades proporcionadas pelo cicloturismo como produto ou consequência da opção por um estilo de vida que busque romper com as pressões da rotina diária. Nessa perspectiva, o ciclismo esportivo não deve ser considerado como cicloturismo, que pode mobilizar a participação de cicloturistas para acompanhar as provas, como ocorre nas competições de elite, no contexto europeu, por exemplo.

O uso da bicicleta como meio de transporte movido à força humana passa a ter outras finalidades com o uso recreativo, de lazer e esporte, a partir das transformações tecnológicas que foram aprimorando e modificando sua qualidade e performance. Os usos da bicicleta no turismo possibilitam um novo olhar sobre a paisagem e o ato de viajar, alterando a noção de tempo/espaço e a relação com o meio. O cicloturismo e o ciclismo se apresentam nas primeiras décadas do século XXI como uma forma sustentável e alternativa de mobilidade frente aos crescentes problemas, com o excesso de veículos automotores e todas as complicações para o meio ambiente.

As inovações tecnológicas produzidas com a popularização da internet e dispositivos móveis, juntamente com as redes sociais, possibilitam outra forma de relação do cicloturismo 
e ciclismo com os trajetos, através do monitoramento por GPS e a interface com as plataformas que tornam a experiência do real ser possivelmente compartilhada e avaliada no virtual. $\mathrm{O}$ pioneirismo de Santa Catarina, com o primeiro roteiro de cicloturismo no Brasil, demonstra as possibilidades existentes para o desenvolvimento de novas práticas e estratégias para o planejamento de novas possibilidades que incentivem e motivem o uso da bicicleta nas viagens, seja de longa, média ou curta duração, desde que com estruturas adequadas às necessidades e expectativas dos ciclistas.

\section{Considerações finais}

Os dados apresentados neste artigo buscam preencher uma lacuna nas pesquisas sobre ciclismo e cicloturismo em Santa Catarina, contribuindo para a coleta de informações para identificar o perfil do ciclista e cicloturista no estado, em seus aspectos socioeconômicos, interesses e motivações no ciclismo e usos de aplicativos de monitoramento.

No contexto catarinense, a participação de homens e mulheres é similar, demonstrando a presença crescente das mulheres em um espaço que, até décadas atrás, era quase exclusivamente masculino. O planejamento dos destinos e atrativos em cicloturismo devem levar em consideração o perfil desse público, com novas demandas e expectativas, conforme a literatura científica vem apontando em nível internacional e nacional.

Os fatores idade, escolarização e renda estão interligados, devido aos custos com a bicicleta e equipamentos de segurança, além da manutenção. Se, no passado, o principal meio para deslocamento dos trabalhadores era a bicicleta, nas últimas décadas, as inovações tecnológicas e técnicas desta atividade esportiva se tornaram acessíveis ao público em geral, embora com valores altos, se comparados à média salarial brasileira. $\mathrm{O}$ consumo de material para ciclismo é variável pela faixa de renda, bem como os deslocamentos para regiões distantes que nem sempre é possível àqueles que não possuem condições financeiras para os custos com translado e estadia.

A compreensão do cicloturismo como sendo o uso da bicicleta para conhecer um território, seja próximo à residência ou distante, independentemente de haver pernoite ou não, é importante para abranger as dinâmicas e especificidades do cicloturismo, que faz parte do turismo como um todo, mas tem suas particularidades ao ser tratado teoricamente e no seu planejamento, na prática.

Os dados apontam o exercício físico como principal motivação para o uso da bicicleta, além da possibilidade de fazer novas amizades, conhecer paisagens e o patrimônio cultural. O 
tempo de movimentação com a bicicleta proporciona o romper com a rotina, tanto da vida pessoal, como profissional e com o uso de veículos automotores, contribuindo para novas relações interpessoais e com o meio ambiente. A tendência apresentada nos dados é uma frequência significativa de dias da semana que são utilizados para pedalar, o que deve ser levado em consideração.

O período noturno também é utilizado para prática do ciclismo e pode ser um elemento a ser agregado para a valorização do cicloturismo, com adequação nos destinos, no que se refere a condições para sua realização. Sinalização e iluminação são fatores que compõem as necessidades do cicloturismo e devem ser levados em consideração no planejamento, principalmente o uso de sinalização específica para os cicloturistas. O uso de GPS é presente no cicloturismo e ciclismo atual, embora nem todos tenham a condição de adquirir ou saibam utilizar de forma apropriada enquanto pedalam, sendo a sinalização importante para auxiliar nos percursos.

Mundos analógicos e digitais necessitam conviver e dialogar para tornar a experiência do pedalar e do cicloturismo bem avaliada e motivar o retorno dos cicloturistas e de seus amigos ao destino. O compartilhamento de percursos e da atividade no aplicativo Strava e as interações geradas nas redes sociais entre os ciclistas demonstram as potencialidades da tecnologia como ferramenta e estratégia de marketing, que necessita ainda de amplos estudos dentro de seus usos no cicloturismo. No contexto desta pesquisa, a maioria dos respondentes tem no Strava uma forma de acompanhar as pedalagens e de divulgar a atividade, com a interação tendo continuidade no mundo virtual. A participação em grupos e/ou equipes é outro ponto a ser levado em consideração para o planejamento, que impacta em uma quantidade maior de pessoas e equipamentos utilizando o espaço ao mesmo tempo.

A concentração de respondentes nas regiões citadas pode ser considerada como um limitador da pesquisa, que poderia ter alcançado um número maior de respondentes, para o desenho de um perfil mais amplo no espaço de moradores de Santa Catarina. A escassez de pesquisas sobre a temática em nível estadual é outro limitador, não sendo possível realizar comparações ou analisar as transformações no uso da bicicleta ao longo de um determinado período. A ausência de dados do turismo catarinense acerca do número de cicloturistas e seus impactos econômicos no mercado também são limitadores para aprofundar análises e estipular resultados, a partir dos dados levantados.

Por ser um tema em expansão na área do turismo, foco deste artigo, o campo para contribuições é amplo, especialmente na avaliação das estruturas e do atendimento de bens e 
serviços nos roteiros de cicloturismo já estabelecidos no estado. As pesquisas dentro dessa temática podem auxiliar em readequações e no planejamento turístico para atender às expectativas e necessidades dos cicloturistas e ciclistas em geral. A análise da importância do cicloturismo e ciclismo para a economia do estado é outro ponto de sugestão e um desafio para futuras pesquisas, identificando a relação do uso da bicicleta dentro do turismo, se não como motivação principal, mas agregado de valor pelo turista, que visita Santa Catarina para desfrutar de suas praias ou dos atrativos da região serrana, por exemplo. O uso da bicicleta nos espaços rurais, pelos moradores, é um tema que necessita de pesquisas, pois o foco é centrado na mobilidade urbana, sem um olhar sobre a realidade presente no referido estado, em municípios de pequeno e médio porte.

As estratégias de marketing para o cicloturismo no estado também surgem como um tema para futuras pesquisas, a fim de se entender como os organizadores desses roteiros tornam cativantes suas propostas frente à diversidade de atrativos turísticos existentes e veiculados em meios de comunicação de massa, como a televisão. Pesquisas sobre os impactos das redes sociais nos roteiros de cicloturismo, seja de forma positiva ou negativa, é outra possibilidade, para avaliar como as marcas projetadas estão sendo consumidas pelo perfil de público esperado e como podem estar motivando outros sujeitos a buscarem esses atrativos no estado.

No século XIX, a bicicleta se tornou uma máquina que revolucionou a forma de locomoção e, no século XXI, vem contribuindo para modificar a relação dos sujeitos com seu meio e transformando as formas de fazer turismo, envolvendo a sustentabilidade, o contato com o patrimônio cultural e natural em outra velocidade de deslocamento e contribuindo para o desenvolvimento das comunidades locais envolvidas. As possibilidades tecnológicas recentes transformam o ato de utilizar a bicicleta no turismo, criando novos significados e representações da importância do pedalar no contexto da sustentabilidade e da mobilidade.

As pesquisas nessa temática, em diferentes áreas do conhecimento, estão em expansão, pelo alcance e pelas formas como a bicicleta vem ganhando novos significados, devido às transformações sociais das últimas décadas, especialmente no Brasil, que tem nos veículos automotores um símbolo de ascensão social e status. Frente às dificuldades e aos desafios, o uso da bicicleta, seja no cotidiano, ou como lazer e esporte, os grupos organizadores de ativismo e ciclismo vem ganhando espaço e pautando as discussões sobre a inserção de políticas públicas que tenham a bicicleta e seus usos como protagonistas. 


\section{Referências}

Allué, A.M. (2019). Deporte, ocio y turismo: el caso del cicloturismo en Catalunya. Revista Española de Educación Física y Deportes, 426 (Esp.), 219-226.

Balassiano, R., Saldanha, L., DeCastro, J., Souza, H.A.S., Telles, R., Garcia, E. \& Amaral, J.P. (2019). O Cicloturista Brasileiro 2018: relatório geral. Rio de Janeiro: Coppe-UFRJ.

Barbosa, L. S. S., Andrade-Matos, M. B. \& Perinotto, A. R. C. (2020). Marketing digital: a influência das mídias sociais digitais no processo de decisão de compra dos consumidores de meios de hospedagem. PODIUM Sport, Leisure and Tourism Review, 9 (1), 154-170.

Campos, A. C., Santos, C.A.J. \& Alves, L.A.C. (2016). Cicloturismo: mobilidade urbana e valorização do turismo da cidade de Aracaju - Sergipe. Revista de Direito da Cidade, 08 (4), 1800-1824.

Cavalcanti, T.S., Santos, A.B.L., Moura, C.B. G. \& Moura, D.L. (2019). "Eu sou Barbie e sou bruta": o empoderamento no ciclismo. Revista Estudos Feminista, 27 (2), 1-15.

Chen, C-F. \& Cheng, W-C. (2016). Sustainability SI: exploring heterogeneity in cycle tourists' preferences for an integrated bike-rail transport service. Networks and Spatial Economics, 16, 83-97.

Cox, P. (2012). Strategies Promoting Cycle Tourism in Belgium: Practices and Implications. Tourism Planning \& Development, 9 (1), 25-39.

Deenihan, G. \& Caulfield, B. (2015). Do tourists value different levels of cycling infrastructure? Tourism Management, 46, (C), 92-101.

Díaz, A. L. (2019). Lo ordinario digital: digitalización de la vida cotidiana como forma de trabajo, Cuadernos de Relaciones Laborales, 37 (2), 313-330.

Edra, F.P.M., Costa, M.L. \& Fernandes, T.T. (2015). Cicloturismo em Niterói: potencialidade a partir do Rio de Janeiro. Caderno Virtual de Turismo, 15 (3), 331-345.

Fernández-Latorre, F.M. (2015). Flujos turísticos, capital territorial y uso de la bicicleta. Andalucía como modelo de destino emergente en cicloturismo. Revista de Estudios Andaluces, 32, 76-107.

Freeman, R. \& Thomlinson, E. (2014). Mountain bike tourism and community development

In British Columbia: critical success factors for the future. Tourism Review International, 18, 9-22.

Gazzola, P., Pavione, E., Grechi, D. \& Ossola, P. (2018). Cycle tourism as a driver for the sustainable development of little-known or remote territories: the experience of the Apennine Regions of Northern Italy. Sustainability, 10 (6), 1-19.

Gil, A.C. (2008). Métodos e técnicas de pesquisa social. São Paulo: Atla. 
Gonçalves-Junior, L., Corrêa, D.A., Carmo, C.S. \& Arévalo, S.T. (2016). Diarios de bicicleta: procesos educativos vivenciados en la Ruta de las Emociones. Estudios Pedagógicos, XLII (1), 323-337.

Hobsbawm, E. (2003). A era dos impérios 1875-1914. São Paulo, Paz e Terra.

Hobsbawm, E. (2004). A era do capital 1848-1875. São Paulo, Paz e Terra.

Klos, R.C., Miskalo-Cruz, M. \& Moraes, L. (2016). Espaço e cicloturismo: a representação urbano-turística de Curitiba/PR em fotografias postadas no Tripadvisor. Marketing \& Tourism Review, 1(2), 1-30.

Kovačić, N. (2015). Profiling bicycle tourists: a case of Croatia. Tourism and Hospitality Management, 21 (2), 159-177.

Lamont, M. (2009). 'Reinventing the wheel: a definitional discussion of bicycle tourism'. Journal of Sport and Tourism, 14 (1), 5-23.

Lee, C-F. (2014). An investigation of factors determining cycling experience and frequency. Tourism Geographies: An International Journal of Tourism Space, Place and Environment, $16(5), 844-862$.

Lee, C-F., Chen, P-T. \& Huang, H-I. (2014). Attributes of destination attractiveness in taiwanese bicycle tourism: the perspective of active experienced bicycle tourists. International Journal of Hospitality \& Tourism Administration, 15, 275-297.

Marconi, E.M. \& Lakatos, M.A. (2017). Metodologia científica. São Paulo: Atlas.

Meng, B. \& Han, H. (2016). Effect of environmental perceptions on bicycle travelers' decision-making process: developing an extended model of goal-directed behavior. Asia Pacific Journal of Tourism Research, 21 (11), 1184-1197.

Moreira, G.O. \& Lovisi, A.L.M. (2017). A utilização da tecnologia da informação em benefício do rendimento de atletas. Caderno de Estudos em Sistemas de Informação, 1 (1), 1-17.

Mrnjavac, E., Kovacic, N. \& Topolšek, D. (2014). The logistic product of bicycle destinations. Tourism and Hospitality Management, 20 (2), 171-184.

Neves, J.O. \& Esperança, J.P. (2011). "Bike usage and cycle tourism: the pattern of portuguese associated bike riders". Tourism \& Management Studies, 1, 191-200.

Pedrini, L. (2013). Cicloturismo no circuito do vale europeu catarinense: Um estudo do comportamento do cliente. Dissertação (Mestrado em Turismo e Hotelaria). Universidade do Vale do Itajaí, Balneário Camboriú.

Piket, P., Eijgelaar, E. \& Peeters, P. (2013). "European cycle tourism: a tool for sustainable regional rural development". Applied Studies in Agribusiness and Commerce, 7 (2-3), 1-5. 
Pires, M.C. (2017). O Brasil, o Mundo e a Quarta Revolução Industrial: reflexões sobre os impactos econômicos e sociais. Revista de Economia Política e História Econômica, 39, 536.

Piwek, L., Joinson, A. \& Morvan, J. (2015). The use of self-monitoring solutions amongst cyclists: An online survey and empirical study. Transportation Research, 77, 126-136.

Resende, J.C. \& Vieira Filho, N.A.Q. (2011). Cicloturistas na Estrada Real: perfil, forma de viagem e implicações para o segmento. Turismo em Análise, 22 (1), 168-194.

Rivers, D.J. (2019). Strava as a discursive field of practice: Technological affordances and mediated cycling motivations. Discourse, Context \& Media, 1-8.

Saldanha, L., Fraga, C. \& Santos, M.P.S. (2015). Discussões preliminares sobre serendipidade, bicicleta e turismo envolvendo a Ilha de Paquetá no Rio de Janeiro (RJ). Caderno Virtual de Turismo, 15 (3), 378-389.

Saldanha, L.E.C., Pereira, L.F., Balassiano, R. \& Fraga, C.C.L. (2020) Cicloturismo no planejamento integrado de cidades e o caso da Região Metropolitana de Curitiba. Revista Turismo em Análise, 31 (2), 296-315.

Schwanen, T. (2015). Beyond instrument: Smartphone app and sustainable mobility. European Journal of Transport and Infrastructure Research. 15 (4), 675-690.

Silva, L. (2007). A procura do turismo em espaço rural. Etnográfica, 11 (1), 141-163.

Slavić, N. (2017). The logistics system of bicycle tourism destination. Tourismos: an International Multidisciplinary Journal of Tourism, 12 (2), 38-69.

Veríssimo e Rodrigues, F.I.B. \& Alexandre, M.L.O. (2020) Tecnologia da Informação no planejamento de viagens e turismo: análise do uso de aplicativos. Revista Iberoamericana de Turismo- RITUR, 10 (1), 130-144.

Unwto (World Tourism Organization). (2014). AM Reports - Global Report on Adventure Tourism. Madrid: UNWTO. 